\title{
New Trend for Acceleration Solid Phase Extraction Process Based on Using Magnetic Nano-adsorbents along with Surface Functionalization through Microwave Assisted Solvent-free Technique
}

\author{
Salwa A. AHMED ${ }^{\dagger}$ and Ezzat M. Soliman \\ Chemistry Department, Faculty of Science, El-Minia University, El-Minia 61111, Egypt
}

\begin{abstract}
The use of a microwave assisted solvent-free technique for silica coating of iron magnetic nanoparticles $\left(\mathrm{Fe}_{3} \mathrm{O}_{4}-\mathrm{MNPs}\right)$ and their functionalization with three aliphatic diamines: 1,2-ethylenediamine (1,2EDA), 1,5-pentanediamine (1,5PDA) and 1.8-octanediamine (1,8-ODA), were successfully achieved in a very short time. Only 60 min were needed for the nano-adsorbent modification as compared with more than 1000 min using conventional methods under reflux conditions. Their surface characteristics (observed by TEM, XRD and FT-IR), in addition to $\mathrm{Cu}$ (II) adsorption capacities (1.805, 1.928 and $2.116 \mathrm{mmol} \mathrm{g}^{-1}$ ) and time of equilibration $(5 \mathrm{~s})$ were almost the same. Thus, the time required to accomplish the solid phase extraction process is greatly reduced. On the other hand, the phenomenon of the fast equilibration kinetics was successfully extended on using the functionalized aliphatic diamines magnetic nano-adsorbents as precursors for further microwave treatment. Three selective magnetic nano-adsorbents $\left(\mathrm{Fe}_{3} \mathrm{O}_{4}-\mathrm{MNPs}-\mathrm{SiO}_{2}-1,2 \mathrm{EDA}-3 \mathrm{FSA}, \mathrm{Fe}_{3} \mathrm{O}_{4}-\right.$ MNPs-SiO ${ }_{2}-1,5 \mathrm{PDA}-3 \mathrm{FSA}$ and $\mathrm{Fe}_{3} \mathrm{O}_{4}-\mathrm{MNPs}_{-} \mathrm{SiO}_{2}-1,8 \mathrm{ODA}-3 \mathrm{FSA}$ ) were obtained via the reaction with 3-formayl salicylic acid (3FSA) as a selective reagent for Fe(III). At $5 \mathrm{~s}$ contact time, they exhibited maximum Fe(III) uptake equal to 4.512 , 4.987 and $5.367 \mathrm{mmol} \mathrm{g}^{-1}$, respectively. Furthermore, modeling of values of metal uptake capacity obtained at different shaking time intervals supports pseudo-second order kinetics.
\end{abstract}

Keywords Solid phase extraction, magnetic nano-adsorbents, microwave heating, 3-formayl salicylic acid

(Received March 30, 2015; Accepted June 22, 2015; Published October 10, 2015)

\section{Introduction}

In analytical methodology, preparing a sample for analysis is an essential step. It must be achieved with due care especially when food, biological and environmental samples are concerned. Since the analyte present in these complex matrices as trace or ultra-trace concentrations, it is necessary to perform not only a selective separation, but also a potential enrichment for the targeted species before its quantification. In fact, solid phase extraction (SPE) is the most commonly used technique for isolation and preconcentration of analytes. ${ }^{1-3}$ However, its use in its classical mode is now too limited. So, several modifications were explored in the last few years for miniaturization and automation of its various stages. Magnetic solid phase extraction (MSPE) is one of the newest approaches in this context, where, magnetic nanoparticles (MNPs) are used as alternatives to conventional SP-extractors. ${ }^{4}$ The use of magnetic nanoadsorbents in MSPE in comparison to conventional adsorbents introduce the following advantages: very large adsorptive surface area, low diffusion resistance, capability of efficient protection either by inorganic or organic coating, very short equilibrium time and unique advantage of fast separation from large volumes under an external magnetic field. ${ }^{5-7}$ In addition,

† To whom correspondence should be addressed.

E-mail: salwa_kasem2003@yahoo.com these magnetic nano-adsorbents were found to be cost effective, simple to use and environmentally sound. For instance, an iron oxide magnetic nanoparticle $\left(\mathrm{Fe}_{3} \mathrm{O}_{4}-\mathrm{MNPs}\right)$ is the mostly commonly used magnetic adsorbent. This is because its coating by silica layer functions as an ideal shell composite to avoid leaching under acidic conditions and redox reaction as well. ${ }^{8,9}$ Moreover, $\mathrm{SiO}_{2}$ coating introduces an abundance of surface hydroxyl groups available for reaction with a reagent of choice to obtain a well protective and a selective magnetic nanoadsorbent $\left(\mathrm{Fe}_{3} \mathrm{O}_{4}-\mathrm{MNPs}-\mathrm{SiO}_{2}\right.$-reagent of choice) able to bind selectively with the aimed analyte. Unfortunately, both the coating and modification processes require multiple steps and are time consuming. ${ }^{10,11}$ To maximize the benefits of these magnetic nano materials, efforts should be directed to reduce the time required for achieving these two basic steps. In this respect, microwave assisted synthesis is expected to be promising. This technique has proven to be superior in terms of very short reaction time in comparison with conventional procedures using traditional heating techniques. Moreover, an environmentally benign dimension has been added to microwave heating protocols by performing reactions on solid supports such as silica and alumina under solvent-free conditions. ${ }^{12,13}$

The aim of this work is to speed up the overall SPE process for $\mathrm{Cu}(\mathrm{II})$ uptake by making the most of both the advantages of fast kinetics of MNPs and short reaction time characteristic for microwave heating for synthesizing silica coating MNPs and aliphatic diamines functionalized adsorbents. Comparing the 
results with the same adsorbents synthesized via conventional heating ${ }^{14,15}$ as a function of $\mathrm{Cu}(\mathrm{II})$ uptake capacities and time of equilibration is also planned to measure the success of the new trend. In fact, diamine functionalized adsorbents are widely used for further reactions with organic reagents to maximize selectivity properties and applications as well. So, it is important to explore if the phenomenon of fast kinetics can be extended. For this purpose the new adsorbents $\left(\mathrm{Fe}_{3} \mathrm{O}_{4}-\mathrm{MNPs}_{-} \mathrm{SiO}_{2-}\right.$ 1,2EDA-3FSA, $\mathrm{Fe}_{3} \mathrm{O}_{4}$-MNPs-SiO${ }_{2}-1,5 \mathrm{PDA}-3 \mathrm{FSA}$ and $\mathrm{Fe}_{3} \mathrm{O}_{4}$ MNPs-SiO ${ }_{2}-1,8 \mathrm{ODA}-3 \mathrm{FSA}$ ) incorporated of 3FSA as $\mathrm{Fe}(\mathrm{III})$ selective reagent ${ }^{16}$ were synthesized under microwave conditions. Characterization and their kinetic performance towards $\mathrm{Fe}(\mathrm{III})$ uptake is designed to be checked.

\section{Experimental}

Materials and methods

Analytical reagent grade ferric chloride hexahydrate $\left(\mathrm{FeCl}_{3} \cdot 6 \mathrm{H}_{2} \mathrm{O}\right)$, ferrous sulphate heptahydrate $\left(\mathrm{FeSO}_{4} \cdot 7 \mathrm{H}_{2} \mathrm{O}\right)$ and copper chloride dihydrate $\left(\mathrm{CuCl}_{2} \cdot 2 \mathrm{H}_{2} \mathrm{O}\right)$ were purchased from Aldrich Chemical Co., USA. Tetraethylorthosilicate (TEOS) was purchased from Sigma Alpha, India. Sodium hydroxide, hydrochloric acid, 3-chloropropyltrimethoxysilane (3-CPTMS), 1,2-ethylenediamine (1,2EDA), 1,5-pentanediamine (1,5PDA), 1,8-octanediamine (1,8ODA) were purchased from BDH, UK. Synthesis of 3-formylsalicilic acid (3FSA) was performed as previously described. ${ }^{16} \mathrm{HCl}$ and $\mathrm{NH}_{4} \mathrm{OH}$ used for justifying the $\mathrm{pH}$ values were purchased from Aldrich Chemical Co., USA.

\section{Instrumentation}

A Fisher Scientific Accumet pH-meter (Model 825, Germany), calibrated against two standard buffer solutions at $\mathrm{pH} 4.0$ and 9.2, was used for $\mathrm{pH}$ measurements. A Wrist Action mechanical shaker Model 75 (manufactured by Burrell Corp., Pittsburgh, PA) was used for shaking. Microwave oven (KOR-131G, Korea) emitting $2.450 \mathrm{GHz}$ microwave frequency, $200-240 \mathrm{~V}$, $50 \mathrm{~Hz}$, microwave input power: $1350 \mathrm{~W}$, microwave energy output: $1000 \mathrm{~W}$ was used for silica coating and functionalization Transmission electron microscopy (TEM) analysis was obtained using a JSM-5400 LV JEOL (Japan). X-ray diffraction (XRD) analysis was carried out using a Philips Co., PW 1370 X-ray diffractometer with $\mathrm{Ni}$ filtered $\mathrm{CuK} \alpha$ radiation $(1.5406 \AA)$. Fourier transform infrared (FT-IR) analysis was measured by FT-IR system spectrometer (Perkin Elmer, England) in the range $4000-400 \mathrm{~cm}^{-1}$.

Synthesis of iron magnetic nano-particles ( $\mathrm{Fe}_{3} \mathrm{O}_{4}$-MNPs)

Magnetic nano-particles $\left(\mathrm{Fe}_{3} \mathrm{O}_{4}\right.$-MNPs) were prepared by the co-precipitation method as described in the literature. ${ }^{17}$

Silica coating and functionalization of $\mathrm{Fe}_{3} \mathrm{O}_{4}-\mathrm{MNPs}$ using microwave synthesis

Silica coated magnetic nanoparticles $\left(\mathrm{Fe}_{3} \mathrm{O}_{4}-\mathrm{MNPs}-\mathrm{SiO}_{2}\right)$. First, $2.0 \mathrm{~mL}$ volume of TEOS was mixed homogenously with $1.0 \mathrm{~g}$ of $\mathrm{Fe}_{3} \mathrm{O}_{4}$-MNPs. The mixture was irradiated in microwave for $30 \mathrm{~min}$ at $20 \mathrm{~W}$ power (as appears in the microwave oven scale refers to $20 \%$ of the value of the microwave output power). The resulting phase was then washed with hot water $\left(60^{\circ} \mathrm{C}\right)$ to remove the residues and excess of TEOS and left to dry in an oven at $60^{\circ} \mathrm{C}$ to give a dark brown product.

Silica coated magnetic nanoparticles functionalized chloromethoxysilane $\left(\mathrm{Fe}_{3} \mathrm{O}_{4}-\mathrm{MNPS}-\mathrm{SiO}_{2}-\mathrm{Cl}\right)$. An amount of $2.0 \mathrm{~mL}$ of 3-chloropropyltrimethoxysilane was mixed well with $1.0 \mathrm{~g}$ of $\mathrm{MNPs}-\mathrm{SiO}_{2}$. The mixture was irradiated with

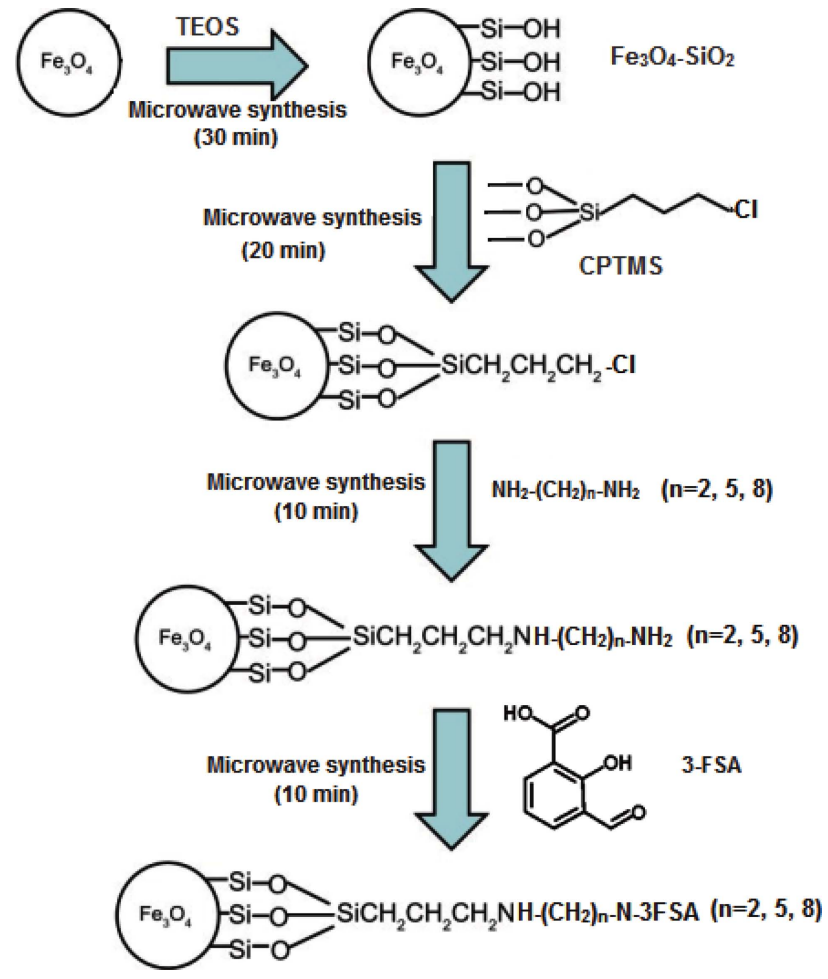

Scheme 1 Synthetic route for microwave functionalized adsorbents.

microwave power of $20 \mathrm{~W}$ for $20 \mathrm{~min}$. The resulting phase was then washed with hot water $\left(60^{\circ} \mathrm{C}\right)$ to remove the residues and excess silylating agent and left to dry in an oven at $60^{\circ} \mathrm{C}$ to give a brown product.

Silica coated magnetic nanoparticles functionalized aliphatic diamines $\left(\mathrm{Fe}_{3} \mathrm{O}_{4}-\mathrm{MNPS}-\mathrm{SiO}_{2}-\mathrm{NH}-\left(\mathrm{CH}_{2}\right)_{n}-\mathrm{NH}_{2}, n=2,5\right.$ and 8). Again, $2.0 \mathrm{~mL}$ each of 1,2EDA, 1,5PDA and $0.173 \mathrm{~g} \mathrm{1,80DA}$ was separately mixed well with $1.0 \mathrm{~g}$ of $\mathrm{Fe}_{3} \mathrm{O}_{4}-\mathrm{MNPs}_{-} \mathrm{SiO}_{2}-\mathrm{Cl}$. The mixture was irradiated with power of $20 \mathrm{~W}$ for $10 \mathrm{~min}$. The resulting phase was then washed with hot water $\left(60^{\circ} \mathrm{C}\right)$ to remove the residues and excess amine and left to dry in an oven at $60^{\circ} \mathrm{C}$ to give a brown product. The three adsorbents obtained

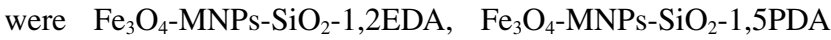
and $\mathrm{Fe}_{3} \mathrm{O}_{4}$-MNPs-SiO $-1,8 \mathrm{ODA}$.

Incorporation of salicylic acid moiety via Schiff's base reaction with silica coated magnetic nanoparticles functionalized aliphatic diamine adsorbents $\left(\mathrm{Fe}_{3} \mathrm{O}_{4}-\mathrm{MNPs}-\mathrm{SiO}_{2}-\mathrm{NH}-\left(\mathrm{CH}_{2}\right)_{n}-\mathrm{N}\right.$ 3FSA, $n=2,5$ and 8 )

An amount of $1.0 \mathrm{~g}$ of $\mathrm{Fe}_{3} \mathrm{O}_{4}$-MNPs-SiO ${ }_{2}$-1,2EDA was added to $1.0 \mathrm{~g}$ of 3-formylsalicilic acid (3FSA) and ground well, then irradiated with power of $20 \mathrm{~W}$ for $10 \mathrm{~min}$. The resulting phase was then washed with hot water $\left(60^{\circ} \mathrm{C}\right)$ and left to dry in an oven at $60^{\circ} \mathrm{C}$ to give a dark green product of the corresponding Schiff base. The same procedure was performed with 1,5PDA and 1,80DA to form the other two Schiff's bases. They were named $\mathrm{Fe}_{3} \mathrm{O}_{4}-\mathrm{MNPs}-\mathrm{SiO}_{2}-1,2 \mathrm{EDA}-3 \mathrm{FSA}, \mathrm{Fe}_{3} \mathrm{O}_{4}-\mathrm{MNPs}_{-} \mathrm{SiO}_{2-}$ 1,5PDA-3FSA and $\mathrm{Fe}_{3} \mathrm{O}_{4}$-MNPs-SiO $\mathrm{S}_{2}-1,8 \mathrm{ODA}-3 \mathrm{FSA}$. A suggested synthetic route for microwave functionalized magnetic nano-adsorbents is illustrated in Scheme 1.

Uptake of $\mathrm{Cu}(\mathrm{II})$ and $\mathrm{Fe}(\mathrm{III})$ by microwave functionalized adsorbents as a function of $\mathrm{pH}$ and shaking time

For uptake of $\mathrm{Cu}$ (II) and $\mathrm{Fe}(\mathrm{III})$ as a function of $\mathrm{pH}, 10.0 \mathrm{mg}$ of the selected magnetic nano-adsorbent was equilibrated with 
$50 \mathrm{~mL}$ solution containing $0.5 \mathrm{~mL}$ of $0.1 \mathrm{M}$ metal ion adjusted with $0.1 \mathrm{M} \mathrm{HCl}$ and $0.1 \mathrm{M} \mathrm{NaOH}$ at the $\mathrm{pH}$ values from 1.0 8.0 for $\mathrm{Cu}$ (II) and from $1.0-4.5$ for $\mathrm{Fe}$ (III) in a $100 \mathrm{~mL}$ measuring flask. Then, the mixture was automatically shaken for $1 \mathrm{~h}(3600 \mathrm{~s})$ at room temperature. The combined magnetic nano-adsorbent with adsorbed metal ion was magnetically separated from the solution under an external magnetic field and the metal ion-free solution was transferred to a conical flask $\mathrm{Cu}(\mathrm{II})$ and $\mathrm{Fe}(\mathrm{III})$ concentrations were determined using complexmetric EDTA titration. For studying the effect of contact time, the same protocol was conducted at optimum $\mathrm{pH}$ values for uptake of $\mathrm{Cu}(\mathrm{II})$ and $\mathrm{Fe}(\mathrm{III})$, and at the selected shaking time $(5,15,30,60,300,600,1200,1800$ and $3600 \mathrm{~s})$.

\section{Results and Discussion}

Silica coating and functionalization of $\mathrm{Fe}_{3} \mathrm{O}_{4}-\mathrm{MNPS}$ using microwave heating under solventless conditions

The use of microwave heating for silica coating and functionalization of $\mathrm{Fe}_{3} \mathrm{O}_{4}$-MNPs considerably reduced the reaction time compared to conventional heating as shown in Table 1. These results are consistent with the direct interaction

between microwave irradiation and reactants..$^{18}$ In this respect, it is well known that in conventional thermal heating, energy is transferred to the sample or reactants through convention, conduction and radiation of heat. In contrast, in microwave heating, energy is directed to materials through molecular interaction with the electromagnetic field. Moreover, in heat

Table 1 Comparison of coating and functionalization processes of $\mathrm{Fe}_{3} \mathrm{O}_{4}$-MNPs using microwave and conventional heating in terms of reaction time

\begin{tabular}{ccc}
\hline Type of reaction & $\begin{array}{c}\text { Time needed } \\
\text { in conventional } \\
\text { method/min }\end{array}$ & $\begin{array}{c}\text { Time needed } \\
\text { in microwave } \\
\text { method/min }\end{array}$ \\
\hline $\begin{array}{l}\text { Coating of } \mathrm{Fe}_{3} \mathrm{O}_{4}-\mathrm{MNPs} \text { with silica } \\
\text { Functionalization of } \mathrm{Fe}_{3} \mathrm{O}_{4} \text {-MNPs } \\
\text { coated silica with aliphatic diamines }\end{array}$ & 300 & 30 \\
$\begin{array}{l}\text { Further functionalization of aliphatic } \\
\text { diamines magnetic nano-adsorbents } \\
\text { with 3FSA }\end{array}$ & 120 & 30 \\
\hline Total time & 1140 & 70 \\
\hline
\end{tabular}
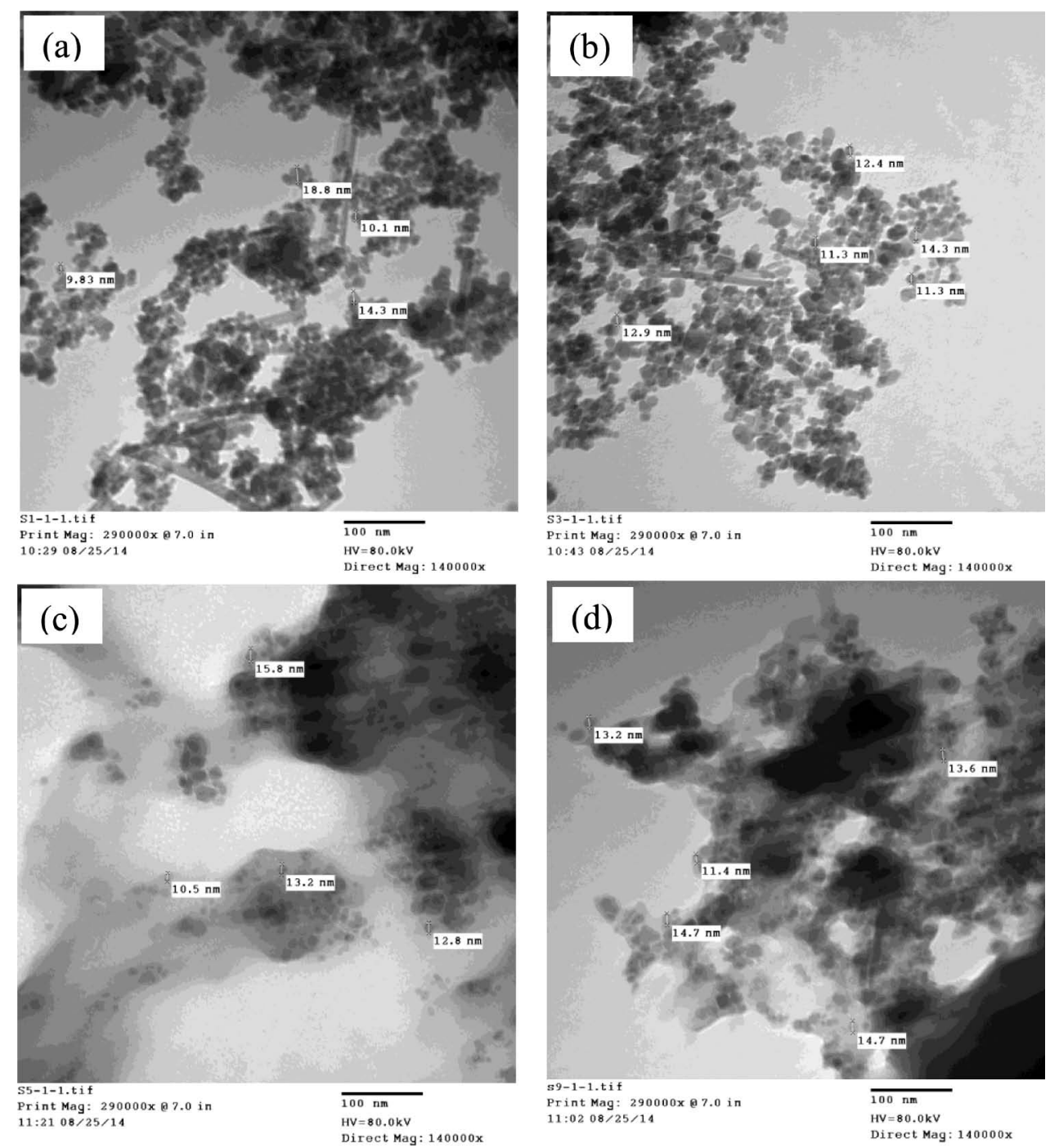

Fig. 1 TEM images of (a) $\mathrm{Fe}_{3} \mathrm{O}_{4}-\mathrm{MNPs}$, (b) $\mathrm{Fe}_{3} \mathrm{O}_{4}-\mathrm{MNPs}-\mathrm{SiO}_{2}$, (c) $\mathrm{Fe}_{3} \mathrm{O}_{4}-\mathrm{MNPs}^{-} \mathrm{SiO}_{2}-1$,8ODA, (d) $\mathrm{Fe}_{3} \mathrm{O}_{4}$-MNPs-SiO ${ }_{2}-1,8 \mathrm{ODA}-3 \mathrm{FSA}$. 
(a)
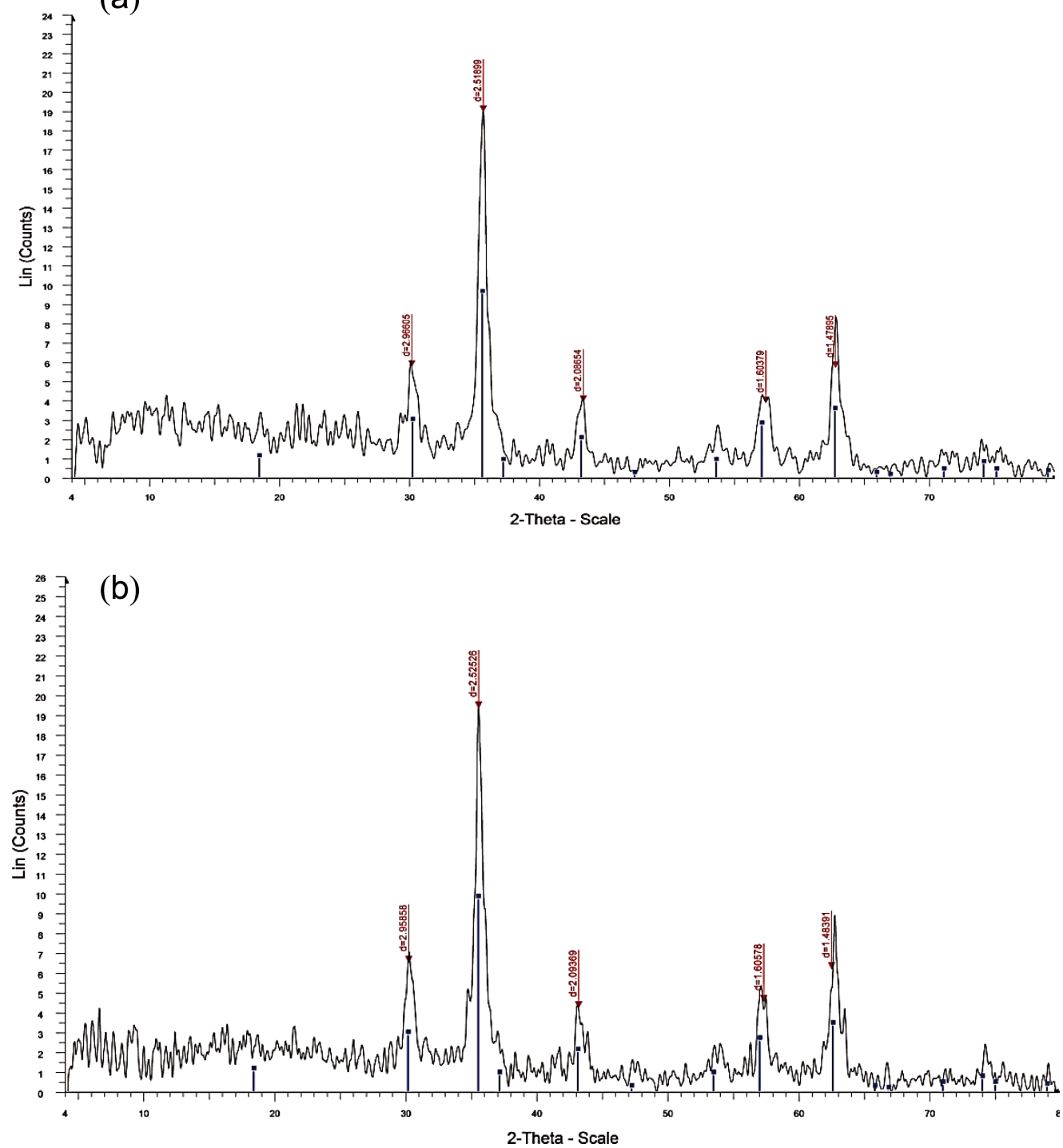

Fig. 2 X-ray diffraction of (a) $\mathrm{Fe}_{3} \mathrm{O}_{4}-\mathrm{MNPs}$ and (b) $\mathrm{Fe}_{3} \mathrm{O}_{4}-\mathrm{MNPs}-\mathrm{SiO}_{2}$.

transfer, energy is transferred due to thermal gradients, but microwave heating is the transfer of electromagnetic energy to thermal energy, rather than heat transfer. ${ }^{18}$ So, one can conclude that specific thermal microwave heating is responsible for a speeding up of chemical reactions, consequently reducing reaction time.

Characterization studies (TEM, X-ray and FT-IR spectral analyses)

In order to characterize the morphology and structure of magnetic nanoparticles $\left(\mathrm{Fe}_{3} \mathrm{O}_{4}\right.$-MNPs), silica coated magnetic nanoparticles $\left(\mathrm{Fe}_{3} \mathrm{O}_{4}-\mathrm{MNPs}-\mathrm{SiO}_{2}\right)$, aliphatic diamines adsorbents $\left(\mathrm{Fe}_{3} \mathrm{O}_{4}-\mathrm{MNPs}-\mathrm{SiO}_{2}-\mathrm{NH}-\left(\mathrm{CH}_{2}\right)_{n}-\mathrm{NH}_{2}, \quad n=2, \quad 5\right.$ and 8$)$ and Schiff's base adsorbents $\left(\mathrm{Fe}_{3} \mathrm{O}_{4}-\mathrm{MNPs}-\mathrm{SiO}_{2}-\mathrm{NH}-\left(\mathrm{CH}_{2}\right)_{n}-\mathrm{N}-\right.$ 3FSA, $n=2,5$ and 8), different techniques such as TEM, XRD and FT-IR analyses were used. Figure 1(a) shows the TEM analysis of $\mathrm{Fe}_{3} \mathrm{O}_{4}$-MNPs reveals that their nanoparticles have sizes $\leq 14.3 \mathrm{~nm}$ (actual size range $9.83-14.3 \mathrm{~nm}$ ). The condensation of silica on the surfaces of the magnetic cores resulted in a fairly core-shell like structure with range 11.3 $14.3 \mathrm{~nm}$ (Fig. 1(b)). Figure 1(c) illustrates that the particle size of $\mathrm{Fe}_{3} \mathrm{O}_{4}$-MNPs-SiO $-1,8 \mathrm{ODA}$ was within the range $10.5-$
15.8 nm. ${ }^{19}$ Finally, the particle size of $\mathrm{Fe}_{3} \mathrm{O}_{4}-\mathrm{SiO}_{2}-1,8 \mathrm{ODA}-$ 3FSA was within the range $11.4-14.7 \mathrm{~nm}$ (Fig. 1(d)). Keeping in mind the advantages of MNPs as previously introduced ${ }^{5-7}$ it is important to note that both the adsorbents, aliphatic diamines and its Schiff's bases still retain particles in the nano-size as the parent $\mathrm{Fe}_{3} \mathrm{O}_{4}$ nanoparticles.

To affirm the $\mathrm{Fe}_{3} \mathrm{O}_{4}$ and $\mathrm{Fe}_{3} \mathrm{O}_{4}-\mathrm{MNPs}-\mathrm{SiO}_{2}$ structure, X-ray diffraction patterns (XRD) were employed. As shown in Figs. 2(a) and 2(b), the powder XRD pattern of the synthesized magnetic nanoparticles was close to the pattern for crystalline magnetite $\mathrm{Fe}_{3} \mathrm{O}_{4}{ }^{20}$ Using the most intense peak in $\mathrm{Fe}_{3} \mathrm{O}_{4}$ nanoparticles XRD pattern, the particle sizes of approximately $9.8-18.8 \mathrm{~nm}$ was estimated by the Debye-Scherer formula, ${ }^{21}$ which was consistent with the results obtained from the TEM image. The characteristic peaks of pure $\mathrm{Fe}_{3} \mathrm{O}_{4}$-MNPs nanoparticles at $20 / \mathrm{deg} .=30.1,35.4,43.9,53.4,57.0$ and 62.6 were also observed for $\mathrm{Fe}_{3} \mathrm{O}_{4}-\mathrm{MNPs}-\mathrm{SiO}_{2}$, confirming the presence of the crystalline structure of the magnetite. Moreover, the intensity of the peaks decreases and becomes slightly wide, indicating the occurrence of coating of non-magnetic and amorphous silica shell onto the surface of $\mathrm{Fe}_{3} \mathrm{O}_{4}$.

Furthermore, the successful coating of $\mathrm{Fe}_{3} \mathrm{O}_{4}$ surface by 


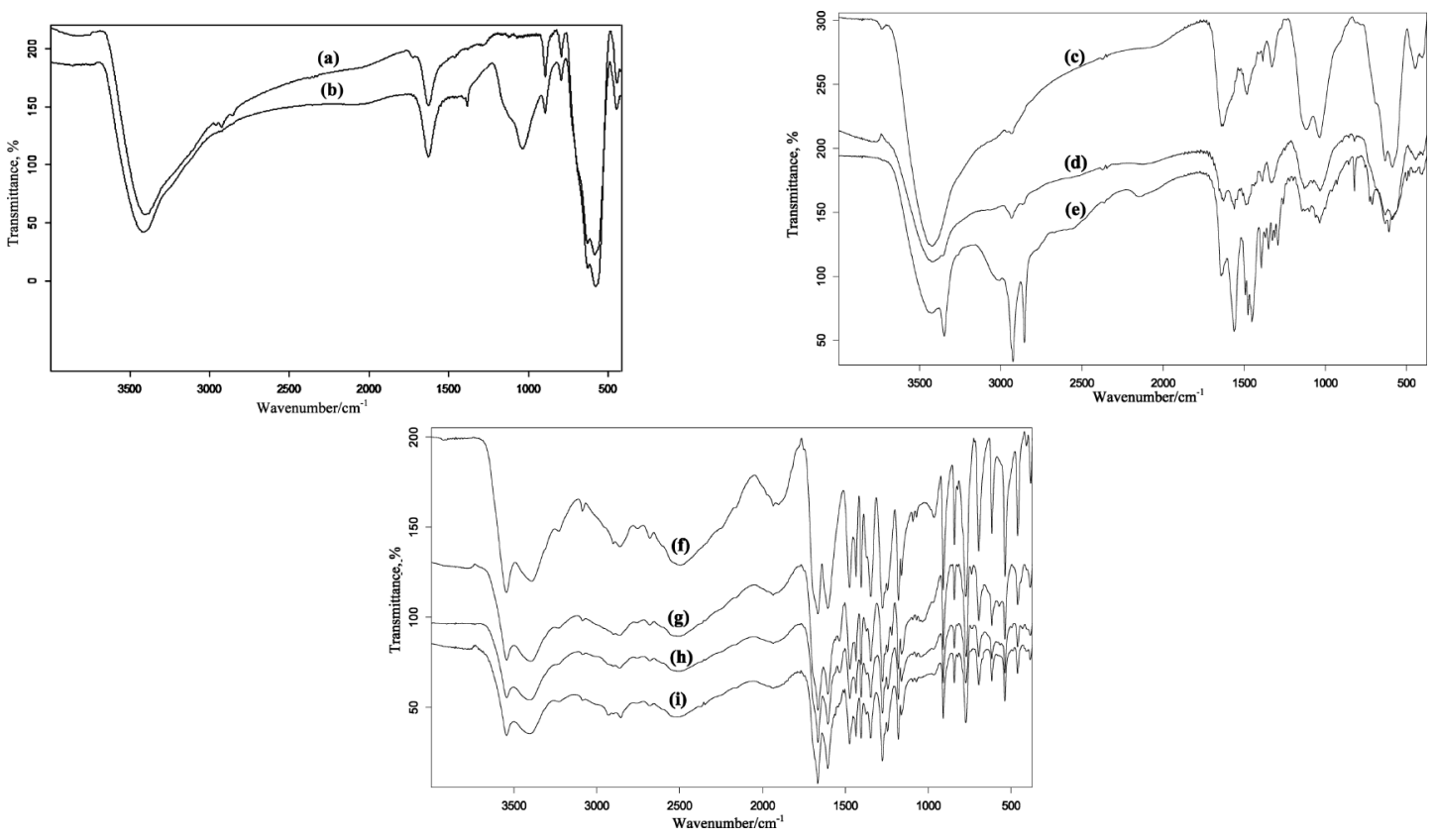

Fig. 3 FT-IR spectra of (a) $\mathrm{Fe}_{3} \mathrm{O}_{4}-\mathrm{MNPs}$, (b) $\mathrm{Fe}_{3} \mathrm{O}_{4}-\mathrm{MNPs}-\mathrm{SiO}_{2}$, (c) $\mathrm{Fe}_{3} \mathrm{O}_{4}-\mathrm{MNPs}-\mathrm{SiO}_{2}-1$,2EDA, (d) $\mathrm{Fe}_{3} \mathrm{O}_{4}-\mathrm{MNPs}-\mathrm{SiO}_{2}-1,5 \mathrm{PDA}$, (e) $\mathrm{Fe}_{3} \mathrm{O}_{4}-\mathrm{MNPs}-\mathrm{SiO}_{2}-1,8 \mathrm{ODA}$, (f) $3 \mathrm{FSA}$, (g) $\mathrm{Fe}_{3} \mathrm{O}_{4}-\mathrm{MNPs} \mathrm{SiO}_{2}-1,2 \mathrm{EDA}-$

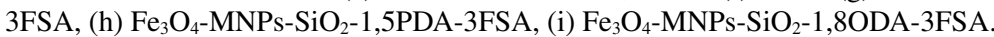
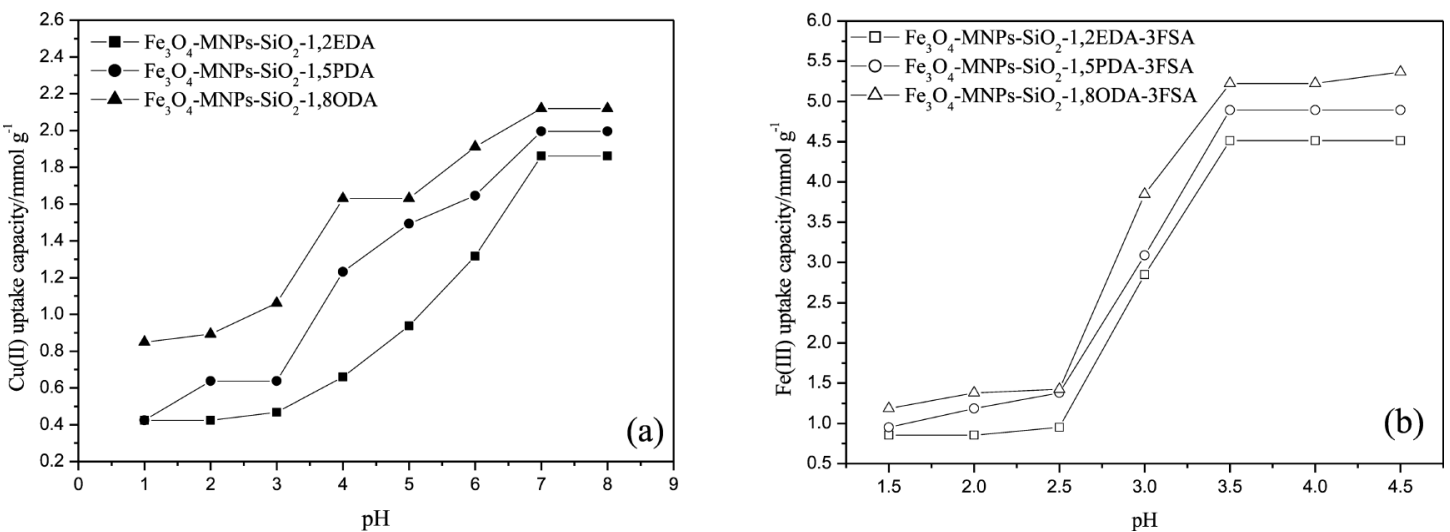

Fig. 4 Effect of $\mathrm{pH}$ on uptake of (a) $\mathrm{Cu}(\mathrm{II})$ and (b) $\mathrm{Fe}(\mathrm{III})$ by magnetic nano-adsorbents.

TEOS, aliphatic diamines functionalization and Schiff's base formation could also be proven by analysis of their FT-IR spectra, Figs. 3(a) - 3(i). As shown in Fig. 3(a), two stretching vibration bands were located at 581 and $631 \mathrm{~cm}^{-1}$ due to $\mathrm{Fe}-\mathrm{O}$ bond incorporated $\mathrm{Fe}_{3} \mathrm{O}_{4}$ in nano-scale dimensions. ${ }^{22}$ They appeared at higher wavenumbers than the characteristic $\mathrm{Fe}-\mathrm{O}$ bond of bulk $\mathrm{Fe}_{3} \mathrm{O}_{4}$ at 570 and $375 \mathrm{~cm}^{-1} .^{22,23}$ This may be taken as criteria to confirm the presence of $\mathrm{Fe}_{3} \mathrm{O}_{4}$ as nanoparticles. ${ }^{24,25}$ Figure 3(b) shows the bands of $\mathrm{Fe}_{3} \mathrm{O}_{4}-\mathrm{SiO}_{2}$ located at 1157, 1027 and $633-589 \mathrm{~cm}^{-1}$ corresponding to the stretching vibration of $v(\mathrm{Si}-\mathrm{O}-\mathrm{Si}), \quad v(\mathrm{Si}-\mathrm{OH}) \quad$ and $\quad v(\mathrm{Si}-\mathrm{O}-\mathrm{Fe})$, respectively. ${ }^{26-29}$ In the FT-IR spectra, the stretching bands are located at 1639, 1628 and $1641 \mathrm{~cm}^{-1}$ for $\mathrm{Fe}_{3} \mathrm{O}_{4}-\mathrm{MNPs}_{-} \mathrm{SiO}_{2}-1,2$ EDA, $\mathrm{Fe}_{3} \mathrm{O}_{4}-\mathrm{MNPs}-\mathrm{SiO}_{2}-1,5 \mathrm{PDA}$ and $\mathrm{Fe}_{3} \mathrm{O}_{4}-\mathrm{MNPs}_{-} \mathrm{SiO}_{2-}$ $1,8 \mathrm{ODA}$, respectively, and these are corresponding to the $\mathrm{NH}_{2}$ bending of free $\mathrm{NH}_{2}$. Moreover, the new additional peaks located in the range of $1563.84-1292.04 \mathrm{~cm}^{-1}$ were attributed to the aliphatic hydrocarbon chain incorporated amine moiety
$v\left(\mathrm{~N}-\left(\mathrm{CH}_{2}\right)_{n}-\mathrm{N}\right)$ stretching vibration, ${ }^{30}$ Figs. 3(c) $-3(\mathrm{e})$.

On the other hand, FT-IR spectral analysis for the adsorbents $\left(\mathrm{Fe}_{3} \mathrm{O}_{4}-\mathrm{MNPs}-\mathrm{SiO}_{2}-\mathrm{NH}-\left(\mathrm{CH}_{2}\right)_{n}-\mathrm{N}-3 \mathrm{FSA}\right)$ as shown in Figs. 3(f) 3(i) ensure Schiff's base formation via microwave condensation reaction between amino and aldehyde groups. ${ }^{31}$ This is based on: a) the appearance of new bands located around $1580 \mathrm{~cm}^{-1}$ due to $v(-\mathrm{C}=\mathrm{N})$ stretching vibration and $\mathrm{b})$ the disappearing of FT-IR band characteristics for free amino group. ${ }^{16}$

Performance of microwave functionalized adsorbents for $\mathrm{Cu}(\mathrm{II})$ and $\mathrm{Fe}(\mathrm{III})$ uptake

Effect of $p H$. The $\mathrm{pH}$ value played a key role in the SPE technique. An appropriate $\mathrm{pH}$ value can improve the adsorption efficiency, and also reduce interference from the matrix. Solution $\mathrm{pH}$ would change the charge property of the adsorbent and the ionized targets thus influence the adsorption of adsorbent to targets. In this context, the results of uptake of $\mathrm{Cu}$ (II) by magnetic nano-adsorbents $\left(\mathrm{Fe}_{3} \mathrm{O}_{4}-\mathrm{MNPs}-\mathrm{SiO}_{2}-1,2 \mathrm{EDA}, \mathrm{Fe}_{3} \mathrm{O}_{4}\right.$ 
MNPs-SiO ${ }_{2}-1,5 \mathrm{PDA}$ and $\mathrm{Fe}_{3} \mathrm{O}_{4}-\mathrm{MNPs}^{-} \mathrm{SiO}_{2}-1,8 \mathrm{ODA}$ ) synthesized by microwave assisted solvent-free approach in the $\mathrm{pH}$ range $1.0-8.0$ showed that the adsorption capacity increased with increasing solution $\mathrm{pH}$ in accordance with decreasing competition with hydrogen ion concentration, Fig. 4(a). At optimum $\mathrm{pH}$ value $(\mathrm{pH} 7.0)$, values of $\mathrm{Cu}(\mathrm{II})$ uptake were evaluated to be $1.862,1.995$ and $2.190 \mathrm{mmol} \mathrm{g}^{-1}$ using $\mathrm{Fe}_{3} \mathrm{O}_{4^{-}}$ MNPs-SiO ${ }_{2}-1,2 \mathrm{EDA}, \mathrm{Fe}_{3} \mathrm{O}_{4}-\mathrm{MNPs}-\mathrm{SiO}_{2}-1,5 \mathrm{PDA}$ and $\mathrm{Fe}_{3} \mathrm{O}_{4-}$ MNPs- $\mathrm{SiO}_{2}-1,8 \mathrm{ODA}$, respectively. These values were comparable with the values $\left(1.852,1.947\right.$ and $\left.2.040 \mathrm{mmol} \mathrm{g}^{-1}\right)$ obtained using the same adsorbents synthesized by the conventional approach, respectively. ${ }^{17}$ On the other hand, the previous diamines adsorbents act as precursor for Schiff's base formation with the chosen 3FSA as selective for Fe(III). So, the

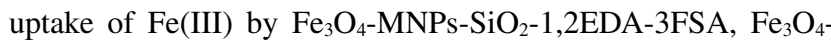

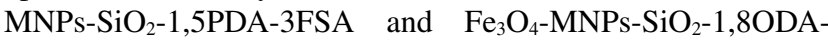
3FSA as a function of $\mathrm{pH}$ (Fig. 4(b)) was also investigated. The results showed maximum uptake capacities at $\mathrm{pH} 3.5$ evaluated to be $4.512,4.987$ and $5.367 \mathrm{mmol} \mathrm{g}^{-1}$ for the above adsorbents, respectively.

Equilibration time for $\mathrm{Cu}(\mathrm{II})$ uptake using $\left(\mathrm{Fe}_{3} \mathrm{O}_{4}-\mathrm{MNPs}_{-} \mathrm{SiO}_{2-}\right.$ $\left.\mathrm{NH}-\left(\mathrm{CH}_{2}\right)_{n}-\mathrm{NH}_{2}\right)$ and $\mathrm{Fe}$ (III) uptake using $\left(\mathrm{Fe}_{3} \mathrm{O}_{4}-\mathrm{MNPs}-\mathrm{SiO}_{2}\right.$ $\mathrm{NH}-\left(\mathrm{CH}_{2}\right)_{n}-\mathrm{N}-3 \mathrm{FSA}, n=2,5$ and 8$)$

The importance of contact time comes from the need to determine the time required to attain equilibrium and consequently the speed of extraction of the target metal ion.

\section{Cu(II) uptake}

The results of $\mathrm{Cu}(\mathrm{II})$ uptake $\left(\mathrm{mmol} \mathrm{g}^{-1}\right)$ as a function of shaking time (s) using the three magnetic nano-adsorbents produced via microwave synthesis are illustrated in Figs. 5(a) and 5(b). Focusing on $\mathrm{mmol} \mathrm{g}^{-1}$ values obtained at four sequential stages including (start, middle and end) of the examined time intervals for $\mathrm{Cu}$ (II) uptake using the adsorbents: $\mathrm{Fe}_{3} \mathrm{O}_{4}$-MNPs-SiO ${ }_{2}-1,2 \mathrm{EDA}, \quad \mathrm{Fe}_{3} \mathrm{O}_{4}$-MNPs-SiO${ }_{2}-1,5 \mathrm{PDA}$ and $\mathrm{Fe}_{3} \mathrm{O}_{4}-\mathrm{MNPs}-\mathrm{SiO}_{2}-1,8 \mathrm{ODA}$ indicate, respectively, the following: $1.805,1.928$ and $2.116 \mathrm{mmol} \mathrm{g}^{-1}$ at $5 \mathrm{~s} ; 1.852,1.947$ and 2.137 mmol g ${ }^{-1}$ at $300 \mathrm{~s}(5 \mathrm{~min}) ; 1.852,1.995$ and 2.190 at $1800 \mathrm{~s}(30$ $\mathrm{min}$ ) and $1.862,1.995$ and $2.190 \mathrm{mmol} \mathrm{g}^{-1}$ at $3600 \mathrm{~s}(60 \mathrm{~min})$. These results clearly indicate that equilibration is very fast and $5 \mathrm{~s}$ is quite enough for quantitative uptake. Their percentage increases do not exceed 3.06, 3.36 and $3.38 \%$, respectively, on performing shaking time at $3600 \mathrm{~s}$ in comparison to only $5 \mathrm{~s}$. On the other hand, these values are too close or better regarding the same adsorbents produced via conventional synthesis recorded to be $1.805,1.900$ and $1.947 \mathrm{mmol} \mathrm{g}^{-1}$, respectively, at 5 s. $^{17}$

\section{$\mathrm{Fe}($ III) uptake}

Values of $\mathrm{Fe}(\mathrm{III})$ uptake as a function of shaking time using the new magnetic nano-adsorbents $\left(\mathrm{Fe}_{3} \mathrm{O}_{4}-\mathrm{MNPs}-\mathrm{SiO}_{2}-1,2 \mathrm{EDA}-\right.$ 3FSA, $\mathrm{Fe}_{3} \mathrm{O}_{4}$-MNPs-SiO${ }_{2}-1,5 \mathrm{PDA}-3 \mathrm{FSA}$ and $\mathrm{Fe}_{3} \mathrm{O}_{4}$-MNPs$\mathrm{SiO}_{2}-1,8 \mathrm{ODA}-3 \mathrm{FSA}$ ) are represented as shown in Figs. 5(c) and 5(d). Surprising results were observed, where fixed Fe(III) uptake values $\left(4.512,4.987\right.$ and $5.367 \mathrm{mmol} \mathrm{g}^{-1}$, respectively) were obtained irrespective to the studied time intervals. The above values were recorded at $5 \mathrm{~s}$ and continued to $3600 \mathrm{~s}$. This behavior emphasizes that, the very fast equilibrium phenomenon is not only realized but also extended. These new adsorbents were produced after further functionalization of their parent diamines. In addition, the order of $\mathrm{Fe}$ (III) uptake values found to be in agreement with increasing aliphatic diamine length $\mathrm{Fe}_{3} \mathrm{O}_{4}$-MNPs-SiO ${ }_{2}-1,2 \mathrm{EDA}-3 \mathrm{FSA}<\mathrm{Fe}_{3} \mathrm{O}_{4}$-MNPs-SiO ${ }_{2}-1,5 \mathrm{PDA}-$ $3 \mathrm{FSA}<\mathrm{Fe}_{3} \mathrm{O}_{4}$-MNPs-SiO${ }_{2}-1,8 \mathrm{ODA}-3 \mathrm{FSA}$ denote to a significant
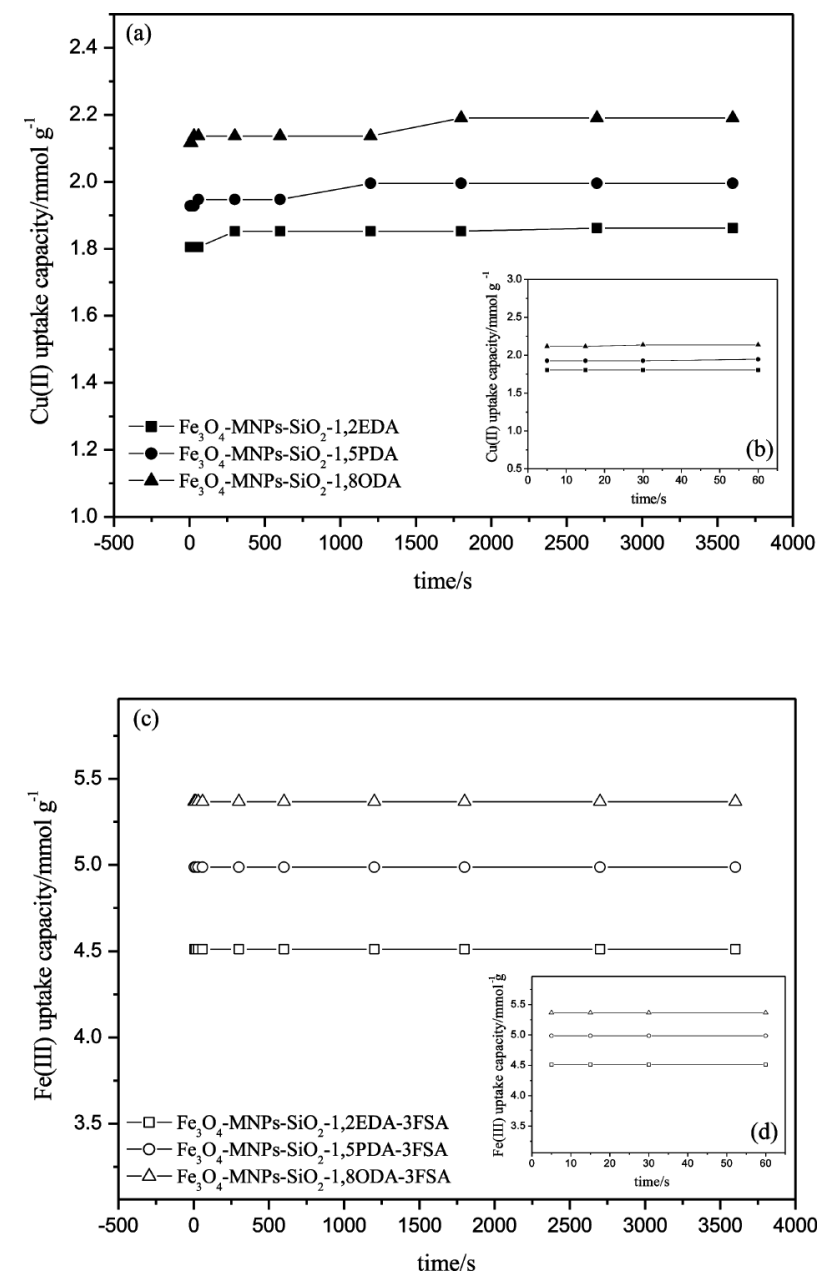

Fig. 5 Effect of time (5-3600 s) and (5-60s) on uptake of (a, b) $\mathrm{Cu}(\mathrm{II})$ and (c, d) $\mathrm{Fe}(\mathrm{III})$ by magnetic nano-adsorbents.

space arm effect. However, the absence of this influence with respect to time needed to attain equilibrium can refer to the possibility of its occurrence below $5 \mathrm{~s}$ or fraction of a second.

\section{Kinetics of $\mathrm{Cu}(\mathrm{II})$ and $\mathrm{Fe}(\mathrm{III})$ uptake}

The adsorption kinetic data of $\mathrm{Cu}(\mathrm{II})$ and $\mathrm{Fe}(\mathrm{III})$ measured on magnetic nano-adsorbents were employed in terms of pseudosecond order adsorption equation. ${ }^{32-34}$ Based on this model, the kinetic rate law can be written as follows:

$$
t / q_{\mathrm{t}}=1 / k_{2} q_{\mathrm{e}}^{2}+\left(1 / q_{\mathrm{e}}\right) t
$$

where $k_{2} q_{\mathrm{e}}^{2}$ is the initial adsorption rate $/ \mathrm{mmol} \mathrm{g}^{-1} \mathrm{~s}^{-1}, k_{2} / \mathrm{g}$ $\mathrm{mmol}^{-1} \mathrm{~s}^{-1}$ is the rate constant of adsorption, $q_{\mathrm{e}} / \mathrm{mmol} \mathrm{g}^{-1}$ is the amount of metal ion sorbed at equilibrium, and $q_{\mathrm{t}} / \mathrm{mmol} \mathrm{g}^{-1}$ the amount of metal ion on the surface of the sorbent at any time $t / \mathrm{s}$. The values of $k_{2} q_{\mathrm{e}}{ }^{2}$ and $q_{\mathrm{e}}$ can be obtained from the intercept and slope of plotting $t / q_{\mathrm{t}} v s . t$ as shown in Figs. 6(a) and 6(b), respectively. For $\mathrm{Cu}$ (II) uptake, it was found that the theoretical $q_{\mathrm{e}}$ values $1.862,1.996$ and $2.193 \mathrm{mmol} \mathrm{g}^{-1}$ were too close to the experimental values $1.852,1.947$ and $2.137 \mathrm{mmol} \mathrm{g}^{-1}$ recorded at $300 \mathrm{~s}$ on using the adsorbents $\mathrm{Fe}_{3} \mathrm{O}_{4}-\mathrm{MNPs}_{-} \mathrm{SiO}_{2}-1$,2EDA, $\mathrm{Fe}_{3} \mathrm{O}_{4}$-MNPs-SiO $-1,5 \mathrm{PDA}$ and $\mathrm{Fe}_{3} \mathrm{O}_{4}$-MNPs-SiO ${ }_{2}-1,8 \mathrm{ODA}$, respectively. Regarding shaking time at $300 \mathrm{~s}$, the percentage increase of $\mathrm{Cu}(\mathrm{II})$ uptake in comparison to only $5 \mathrm{~s}(1.805$, 1.928 and $2.116 \mathrm{mmol} \mathrm{g}^{-1}$ ) did not exceed 2.54, 0.97 and $0.98 \%$, 

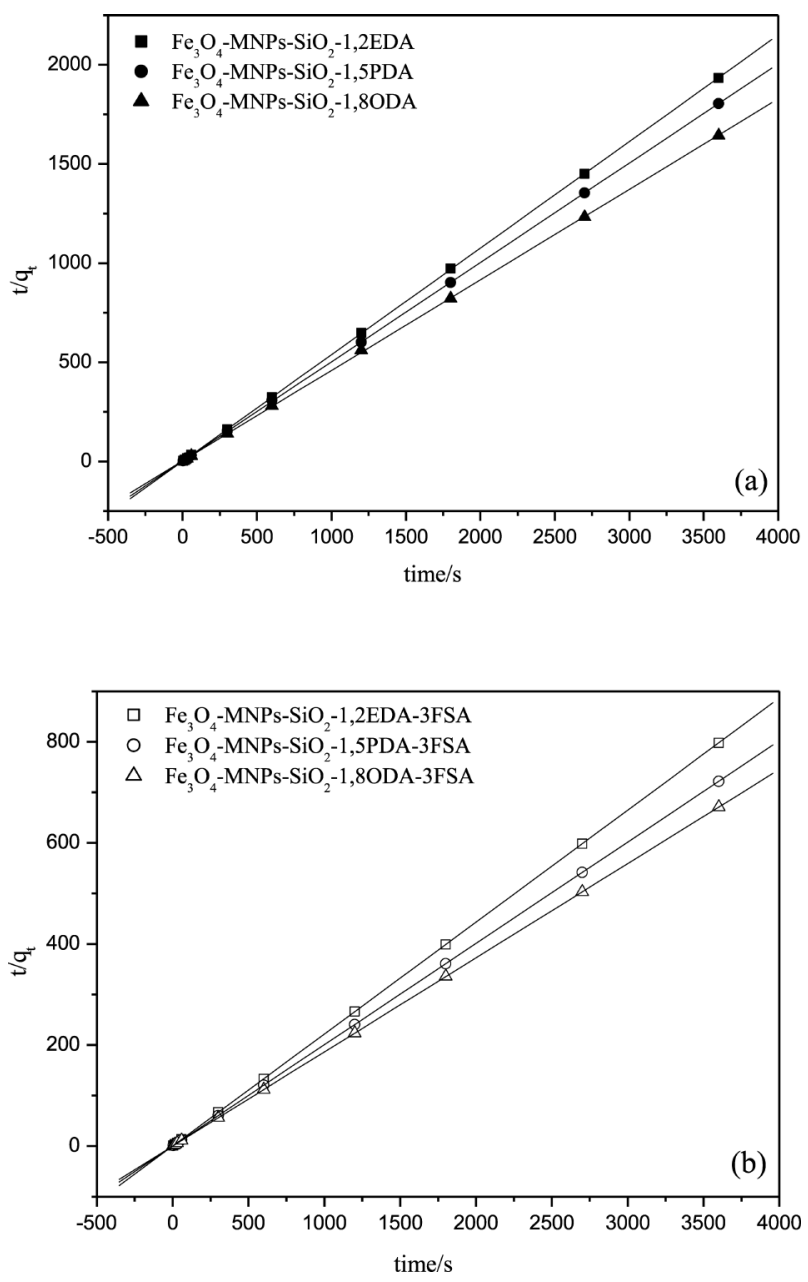

Fig. 6 Pseudo-second-order kinetic plot for the adsorption of (a) $\mathrm{Cu}(\mathrm{II})$ and (b) $\mathrm{Fe}(\mathrm{III})$ on magnetic nano-adsorbents.

respectively. This confirmed again that $5 \mathrm{~s}$ is still quite enough for quantitative uptake. With respect to $\mathrm{Fe}(\mathrm{III})$ uptake using

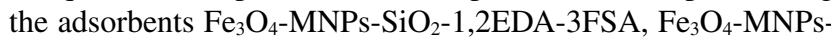
$\mathrm{SiO}_{2}-1,5 \mathrm{PDA}-3 \mathrm{FSA}$ and $\mathrm{Fe}_{3} \mathrm{O}_{4}$-MNPs-SiO${ }_{2}-1$,8ODA-3FSA, the theoretical $q_{\mathrm{e}}$ values $4.504,5.000$, and $5.376 \mathrm{mmol} \mathrm{g}^{-1}$ were in good agreement with the experimental values 4.512, 4.987 and $5.367 \mathrm{mmol} \mathrm{g}^{-1}$ recorded at $5 \mathrm{~s}$, respectively. Finally, these results along with $r^{2}$ values $(0.999-1.0)$ seem to be in harmony with a pseudo-second-order kinetic model.

\section{Conclusions}

Due to the increasing need for accelerating the SPE process as a whole, a new trend has been introduced. Its main features can be outlined in the following two concepts:

1- Reduction of the time required for surface functionalization of $\mathrm{Fe}_{3} \mathrm{O}_{4}$-MNPs to act as a parent adsorbent core by utilizing a microwave solvent-less technique.

2- Shortening the equilibration time for uptake of the target analyte by adapting functionalized $\mathrm{Fe}_{3} \mathrm{O}_{4}$-MNPs. In addition, making use of their unique characteristics for separation under the influence of an external magnetic field.

By applying the above two concepts, the following were achieved: a) A drastic reduction of time from many hours to a few minutes for performing silica coating and functionalization for $\mathrm{Fe}_{3} \mathrm{O}_{4}$-MNPs using a microwave solvent-free synthesis technique. Moreover, the essential property regarding the nano size of $\mathrm{Fe}_{3} \mathrm{O}_{4}$ particles $(9.83-14.3 \mathrm{~nm})$ was still maintained after modification either by aliphatic diamine $(10.5-15.8 \mathrm{~nm})$ or formyl salicylic acid $(11.4-14.7 \mathrm{~nm})$ as proven by TEM analysis.

b) Only 5 seconds were recorded for $\mathrm{Cu}$ (II) uptake using the diamine adsorbents $\left(\mathrm{Fe}_{3} \mathrm{O}_{4}-\mathrm{MNPs}-\mathrm{SiO}_{2}-\mathrm{NH}-\left(\mathrm{CH}_{2}\right)_{n}-\mathrm{NH}_{2}\right.$, $n=2,5$ and 8 ) demonstrating very fast equilibration.

c) Continuation of the phenomenon of fast equilibration time on using the adsorbents $\mathrm{Fe}_{3} \mathrm{O}_{4}-\mathrm{MNPs}-\mathrm{SiO}_{2}-\mathrm{NH}-\left(\mathrm{CH}_{2}\right)_{n}-\mathrm{N}-$ $3 \mathrm{FSA},(n=2,5$ and 8$)$ produced via further functionalization of the parent diamines, for $\mathrm{Fe}(\mathrm{III})$ uptake.

In view of this mode of fast kinetics and regarding values of nano-size particles of the used adsorbents, one can satisfactorily assume that on using selective magnetic nano-adsorbents with particle size $<15 \mathrm{~nm}$, the studies concerning the effect of contact time intervals of less than $60 \mathrm{~s}$ is quite adequate for assessment of the equilibration time required for uptake of the target analyte. In other words, equilibration time $\leq 5 \mathrm{~s}$ can be taken as a criteria for a nano-particle size adsorbent $<15 \mathrm{~nm}$.

\section{References}

1. Z. A. Alothman, E. Yilmaz, M. Habila, and M. Soylak, Ecotox. Environ. Safe, , 2015, 112, 74.

2. T. Dasbas, S. Saçmac, A. Ülgen, and S. Kartal, Food Chem., 2015, 174, 591.

3. M. Ghaedi, K. Niknam, S. Zamani, H. A. Larki, M. Roosta, and M. Soylak, Mater. Sci. Eng. C, 2013, 33, 3180.

4. M. Wierucka and M. Biziuk, TrAC, Trends Anal. Chem., 2014, 59, 50 .

5. Y. Pang, G. Zeng, L. Tang, Y. Zhang, Y. Liu, X. Lei, Z. Li, J. Zhang, Z. Liu, and Y. Xiong, Chem. Eng. J., 2011, 175, 222.

6. S. C. N. Tang and I. M. C. Lo, Water Res., 2013, 47, 2613.

7. L. Chen, T. Wang, and J. Tong, TrAC, Trends Anal. Chem., 2011, 30, 1095.

8. P. I. Girginova, A. L. Daniel-da-Silva, C. B. Lopes, P. Figueira, M. Otero, V. S. Amaral, E. Pereira, and T. Trindade, J. Colloid Interface Sci., 2010, 345, 234.

9. J. H. Jang and H. B. Lim, Microchem. J., 2010, 94, 148.

10. B. Maddah and J. Shamsi, J. Chromatogr. A, 2012, 1256, 40.

11. M. E. Mahmoud, M. S. Abdelwahab, and E. M. Fathallah, Chem. Eng. J., 2013, 223, 318.

12. P. Lidstro, J. Tierney, Be. Wathey, and J. Westman, Tetrahedron, 2001, 57, 9225.

13. R. S. Varma, Green Chem., 1999, 1, 43.

14. A. Ghorbani-Choghamarani and M. Norouzi, J. Mol. Catal. A, 2014, 395, 172.

15. M. E. Mahmoud, M. S. Abdelwahab, and E. M. Fathallah, Chem. Eng. J., 2013, 223, 318.

16. M. E. Mahmoud and E. M. Soliman, Talanta, 1997, 44, 15

17. S. A. Ahmed and E. M. Soliman, Anal. Sci., 2014, 30, 823.

18. E. T. Thostenson and T. W. Chou, Composites A, 1999, 30, 1055.

19. S. Sadeghi, H. Azhdari, H. Arabi, and A. Z. Moghaddam, J. Hazard. Mater., 2012, 215 - 216, 208.

20. H. Arabi, S. Nateghi, and S. Sadeghi, Solid State Phenom., 2009, 152 - 153, 205. 
21. H. P. Klug, and L. E. Alexander, "X-ray Diffraction Procedures for Polycrystalline and Amorphous Materials", 1962, John Wiley and Sons, New York.

22. A. Khan, Mater. Lett., 2008, 62, 898.

23. R. D. Waldron, Phys. Rev., 1995, 99, 1727.

24. M. Ma, Y. Zhang, W. Yu, H. Y. Shen, H. Q. Zhang, and N. Gu, Colloids Surf., A, 2003, 212, 219.

25. Y. S. Li, J. S. Church, and A. L. Woodhead, J. Magn. Magn. Mater, 2012, 324, 1543.

26. P. I. Girginova, A. L. Daniel-da-Silva, C. B. Lopes, P. Figueira, M. Otero, V. S. Amaral, E. Pereira, and T. Trindade, J. Colloid Interface Sci., 2010, 345, 234.

27. M. E. Mahmoud, M. M. El-Essawi, and E. M. I. Fathallah, J. Liq. Chromatogr. Relat. Technol., 2004, 27, 1711.
28. S. Goubert-Renaudin, R. Schneider, and A. Walcarius, Tetrahedron Lett., 2007, 48, 2113.

29. I. J. Bruce and T. Sen, Langmuir, 2005, 21, 7029.

30. E. Pretsch, T. Clerc, J. Seibl, and W. Simon, "Tables of Spectral Data for Structure Elucidation of Organic Compound", 2nd ed., 1989, Springer-Verlag, Berlin.

31. R. S. Varma, R. Dahiya, and S. Kumar, Tetrahedron Lett., 1997, 38, 2039.

32. M. Najafi, Y. Yousefi, and A. A. Rafati, Sep. Purif. Technol., 2012, 85, 193.

33. Y. S. Ho and G. McKay, Process Biochem., 1999, 34, 451.

34. M. Naushad, Z. A. ALOthman, Inamuddin, and H. Javadian, J. Ind. Eng. Chem., 2014, in press. 